\title{
Circulatory Effects of Sodium Nitroprusside in the Conscious Lamb with an Aortopulmonary Left to Right Shunt ${ }^{1}$
}

\author{
G. PAUL TOOROP, ${ }^{2}$ RUDI HARDJOWIJONO ${ }^{3}$ JAN H. KOERS, MARLON J. VAN STRAALEN, \\ CHARLES R. H. WILDEVUUR, WILLEM G. ZIJLSTRA, AND JAAP R. G. KUIPERS
}

From the Departments of Pediatrics, Thoracic Surgery [R.H., C.R.H.W.] and Physiology [W.G.Z.], University of Groningen, Groningen, The Netherlands

\begin{abstract}
We studied the effect on the circulation of reducing peripheral vascular resistance by infusing sodium nitroprusside into lambs of three different age groups (subgroup A, 11-26 days, subgroup $B, 32-52$ days, and subgroup $C, 61-88$ days of age) with and without an aortopulmonary left to right shunt. Infusion of $10 \mu \mathrm{g} / \mathrm{kg} /$ min nitroprusside over $2 \mathrm{~h}$ decreased aortic and left atrial pressures markedly and increased heart rate, whereas systemic, pulmonary, and left to right shunt blood flows hardly changed. Within $30 \mathrm{~min}$ after the onset of infusion, the hemodynamic variables stabilized. Aortic and left atrial pressures were still below control levels at that time. The different flows remained the same and heart rate, after an initial fall, increased again. The pattern of hemodynamic changes was not influenced by age or the presence of an aortopulmonary left to right shunt. Based on this study, we do not advocate sodium nitroprusside administration in case of a left to right shunt with normal arterial pressure and systemic blood flow. (Pediatr Res 25:44-48, 1989)
\end{abstract}

Afterload reduction has been widely used in patients with impaired ventricular performance $(1,2)$. Until recently, experience with afterload reduction in the pediatric age group was limited (3). However, because acute experimental studies first showed the dilatation of systemic resistance vessels diminished the magnitude of a left to right shunt across a ventricular septal defect (4), vasodilator treatment of infants with such a defect has become more common (5-7).

The results of these studies, however, show no uniformity. This might be a result of the selection of patients or the type of vasodilator used or it might result from the timing of the hemodynamic measurements. The measurements may have been taken before hemodynamic stabilization had set in. This stabilization may take some time, as was shown during the infusion of sodium nitroprusside into lambs without a shunt (8). Consequently, measurement of the instantaneous hemodynamic

Received August 14, 1987; accepted September 7, 1988

Correspondence Jaap R. G. Kuipers, M.D., Division of Pediatric Cardiology, Department of Pediatrics, University Hospital, Oostersingel 59, 9713 EZ Gronin gen, The Netherlands.

This work was supported by Grant 79.056 from the Netherlands Heart Foundation.

${ }^{1}$ Presented in part at the Annual Scientific Session of the European Society for Pediatric Research, September 1982, Jerusalem.

${ }^{2}$ Present address: Organon Registration Unit, P.O. Box 20, 5340 BH Oss, The Netherlands.

${ }^{3}$ Present address: Onze Lieve Vrouwe Gasthuis, le Oosterparkstraat 179, 1091 HA Amsterdam, The Netherlands. changes evoked by a vasodilator over a longer period would be preferable. However, in patients this is not feasible.

Therefore, we designed the present study with the objectives to examine the changes in pulmonary, systemic, and left to right shunt blood flow caused by sodium nitroprusside in lambs with an aortopulmonary left to right shunt and to compare these hemodynamic changes to those in lambs without a shunt. Moreover, we wanted to assess the influence of age on the response to sodium nitroprusside. Sodium nitroprusside was chosen because it dilates not only arterial but also venous vessels (9), which in case of a substantial left to right shunt could reduce the increased preload favorably.

\section{MATERIALS AND METHODS}

A total of 38 lambs of mixed breed and documented birth dates were studied. They were divided into two groups: lambs with (S) and without an aortopulmonary left to right shunt (C). Each group was split into three subgroups according to their age on the day of the study: A (11-26 days), B (33-52 days), and C (61-88 days). Throughout the study, each lamb remained with its mother except for the lambs of subgroup C.

Surgical Procedures. Anesthesia was induced by inhalation of $2-3 \%$ halothane in oxygen. The lamb was intubated with a cuffed endotracheal tube, placed on a warming pad, and ventilated with $0.5-1.0 \%$ halothane in oxygen by an Engström intermittent positive-pressure respiratory pump (Engström, Bromma, Sweden). Inspiratory volume was $10-15 \mathrm{ml} / \mathrm{kg}$. The initial pump frequency was $15-20 \mathrm{cycles} / \mathrm{min}$, and end tidal pressure was 2 $\mathrm{cm}_{2} \mathrm{O}$. Analgesia was maintained with $2 \mathrm{mg} / \mathrm{kg}$ intramuscular piritramide.

Using sterile techniques, we performed a left thoracotomy in the third or fourth intercostal space. Polyvinyl catheters (i.d. 1.0 $\mathrm{mm}$, o.d. $1.5 \mathrm{~mm}$ ) were inserted into the internal thoracic artery and vein, and advanced to the brachiochephalic trunk and superior vena cava, respectively. The pericardium was incised over the main pulmonary artery. Special care was taken not to damage the sympathetic and vagus nerves. In the shunt lambs, after removal of connective tissue around the aorta and pulmonary artery, a Goretex conduit (i.d. 6 or $8 \mathrm{~mm}$; W.L. Gore and Assoc. Inc., Flagstaff, AZ) was sutured between the descending aorta, at the level of the fibrotic string of the ductus arteriosus, and the main pulmonary artery. Through purse string sutures, catheters were inserted into the pulmonary artery, the right ventricle, and through the left atrial appendage, into the body of the left atrium. Precalibrated electromagnetic flow transducers (i.d. 9-15 mm; Skalar Medical, Delft, The Netherlands) were placed around the ascending aorta just above the coronary arteries and around the pulmonary artery proximal to the conduit. An $8 \mathrm{~F}$ polyvinyl catheter was placed in the left pleural 
cavity for chest drainage. No attempt was made to close the pericardium. All catheters and the two flow transducer cables were led to the skin on the left flank and protected by a Teflon cloth pouch that was sewn to the skin after the chest had been closed in layers.

For the control lambs, surgical instrumentation was the same, except for the conduit, the flow transducer around the aorta, and the right ventricular catheter. All catheters except the one for chest drainage were filled with heparin and plugged.

On the day of surgery and days 1-4 postoperatively, we injected $50 \mathrm{mg} / \mathrm{kg}$ of ampicillin intramuscularly. Moreover, once a week we injected $300 \mathrm{mg}$ of iron intramuscularly and gave aspirin in an oral dose of $10 \mathrm{mg} / \mathrm{kg}$ to prevent conduit thrombosis in the shunt lambs. The heparin was drained from the catheters daily, after which they were flushed with $0.9 \%$ saline solution and refilled with heparin. We allowed the lambs at least 3 days to recover from surgery before starting the experiments (10).

Experimental Protocols. Preinfusion protocol. The lambs were allowed to feed until $2 \mathrm{~h}$ before the measurements. Then they were weighed and placed in a canvas sling which supported them in the upright position. Data were collected only when the lambs were calm and resting. During the preinfusion period in the shunt lambs, pulmonary blood flow minus coronary blood flow and systemic blood flow were measured continuously with the electromagnetic flow transducers around the aorta and the pulmonary artery, respectively. Moreover, we measured aortic, pulmonary arterial, left atrial, and central venous pressures every 5 min. Blood samples were withdrawn from the aorta to determine blood gases, $\mathrm{pH}$, and $\mathrm{Hb}$ concentration. Because ambient temperature influences oxygen consumption and cardiovascular function both at rest and during stress (11), we kept it between $22-23^{\circ} \mathrm{C}$. Preinfusion measurements were taken for a $30-\mathrm{min}$ period. In the control lambs, we only measured pulmonary blood flow as this equals systemic blood flow.

Nitroprusside protocol. We infused sodium nitroprusside in quantities of 5 and $10 \mu \mathrm{g} / \mathrm{kg} / \mathrm{min}$ for 1 and $2 \mathrm{~h}$, respectively, and measured the same hemodynamic variables as during the preinfusion period. After the infusion of $5 \mu \mathrm{g} / \mathrm{kg} / \mathrm{min}$ nitroprusside, we studied the lambs for a 30 -min recovery period, whereas the lambs infused with $10 \mu \mathrm{g} / \mathrm{kg} / \mathrm{min}$ of nitroprusside were studied for a 60-min recovery period. The sequence of the two concentrations of nitroprusside infusion was randomized. The interval between the two studies was $48 \mathrm{~h}$ or more.

Measurements and Calculations. Aortic, pulmonary arterial, left atrial, and systemic venous pressures were measured with Gould P23 ID transducers (Spectramed Inc., Oxnard, CA) referenced to atmospheric pressure with 0 obtained at the mid-chest position. The precalibrated electromagnetic flow transducers were connected to Skalar MDL 400 flow meters. Heart rate was obtained from the blood flow signal with the aid of a cardiotachometer. All variables were recorded on an Elema Mingograf 800 ink-jet recorder (Siemens-Elema AB, Solna, Sweden). Blood gas tensions and $\mathrm{pH}$ were measured with a Radiometer ABL2 blood gas analyzer (Radiometer A/S, Copenhagen, Denmark); $\mathrm{Hb}$ concentration was measured by the cyanmethemoglobin method. The left to right shunt flow was calculated by subtracting systemic from pulmonary blood flow, and the left to right shunt fraction was obtained by dividing left to right shunt flow by pulmonary blood flow. Pulmonary and systemic vascular resistance were calculated according to standard equations.

Analysis. Results are expressed as means \pm SEM. Statistical analysis was done separately for each variable. Two-way analysis of variance with replication and unequal samples was used within the shunt and the control lambs to test the response to the infusion of nitroprusside, the effect of age and their interaction (12). The same was done within the age-related subgroups of shunt and control lambs to test the response to the infusion of nitroprusside, the effect of the presence of a left to right shunt, and their interaction. One-way analysis of variance was used for the pooled data of the left to right shunt flow and fraction to test the response to sodium nitroprusside. The statistical significance of differences was determined by the Newman-Keuls procedure (13). A value of $p<0.05$ was accepted as significant.

\section{RESULTS}

The ages and weights, the mean arterial $\mathrm{pH}$, blood gases, and $\mathrm{Hb}$ concentrations of the three subgroups of the shunt and control lambs are given in Table 1. Within each age group, these variables were not significantly different between shunt and control lambs. Preinfusion hemodynamic data are in Table 2. There were some significant age-related differences in resting hemodynamic variables within the shunt group and within the control group. Heart rate in subgroup A was higher than in subgroup $C$ of the shunt lambs and subgroups $B$ and $C$ of the control lambs. In addition, systemic blood flow was higher in subgroup A without a shunt, as compared with subgroups B and C. Systemic vascular resistance in subgroup A with a shunt was lower than in subgroup B.

Pulmonary blood flows in all lambs with a shunt were higher than in age-matched controls. Left atrial pressures tended to be higher in lambs with a shunt but was significant only in subgroup $B$. Heart rates in lambs with a shunt in subgroups B and C were significantly higher than in the age-matched control lambs. Similarly, the systemic vascular resistance in subgroup B of the shunt lambs was significantly higher than in the control lambs.

Responses to Nitroprusside. Because the effects of the infusions of 5 and $10 \mu \mathrm{g} / \mathrm{kg} / \mathrm{min}$ were qualitatively similar, only the effects of the $10 \mu \mathrm{g} / \mathrm{kg} / \mathrm{min}$ infusion will be reported (Fig. 1, Table 2). About 2 to $3 \mathrm{~min}$ after the onset of the infusion, mean aortic blood pressure fell consistently, whereas left atrial pressure, heart rate, and cardiac output fluctuated for about $15 \mathrm{~min}$. Then there was a gradual adjustment, and at $30 \mathrm{~min}$ after the onset of the infusion, all hemodynamic variables were stable until the end of the infusion.

The significant fall in mean aortic blood pressure reached its nadir at about $5 \mathrm{~min}$ after the onset of the infusion in all subgroups (Fig. 1). After the maximum decrease, the mean aortic pressure gradually increased again to values that were still significantly lower than the preinfusion values, except for those in subgroups B and C of the shunt lambs (Table 2). After the end of the infusion the mean aortic blood pressure increased significantly in all subgroups to values which were even significantly higher than the preinfusion values, except for subgroup $A$ of the shunt lambs.

Left atrial pressure tended to decrease in all subgroups and increased again after the end of the nitroprusside infusion. Throughout the entire study period, left atrial pressures in subgroup B were at corresponding times almost always higher in lambs with a shunt than in control lambs.

Heart rate increased immediately after the onset of nitroprusside infusion in all subgroups. After this initial increase, heart rate fell and then increased again, but now more gradually, to reach a plateau within $30 \mathrm{~min}$. Except for subgroups $A$ and $B$ of the shunt lambs, heart rates were now significantly higher than during the preinfusion period. After the end of the infusion period, heart rate rapidly fell to preinfusion values. At $60 \mathrm{~min}$, subgroups B and C of the control lambs had significantly lower heart rates than subgroup $A$.

Initially, systemic blood flow tended to increase, but after this initial increase, it fell close to preinfusion values and remained at this level until the end of the infusion period. During the nitroprusside infusion in the control as well as in the shunt lambs, groups B and C had significantly lower systemic blood flows at corresponding times than group $\mathrm{A}$.

Pulmonary blood flow did not change significantly in the shunt lambs during the infusion of nitroprusside. At corresponding times, pulmonary blood flow was always significantly higher in the shunt lambs than in the age-matched control lambs. The left 
Table 1. Wt and ages, and arterial pH, blood gas data, and Hb concentration during the preinfusion period in three age groups of shunt and control lambs*

\begin{tabular}{|c|c|c|c|c|c|c|}
\hline Groups & & Shunt & & & Control & \\
\hline Subgroups & A & $\mathrm{B}$ & $\mathrm{C}$ & A & B & $\mathrm{C}$ \\
\hline$n$ & 8 & 6 & 5 & 6 & 7 & 6 \\
\hline Age (days) & $22 \pm 2$ & $44 \pm 3$ & $70 \pm 3$ & $17 \pm 2$ & $41 \pm 2$ & $81 \pm 4$ \\
\hline Wt $(\mathrm{kg})$ & $9.9 \pm 0.9$ & $16.3 \pm 1.0$ & $19.3 \pm 1.7$ & $7.6 \pm 0.8$ & $14.0 \pm 1.1$ & $22.8 \pm 2.4$ \\
\hline $\mathrm{pH}$ & $7.40 \pm 0.02$ & $7.41 \pm 0.04$ & $7.45 \pm 0.03$ & $7.40 \pm 0.02$ & $7.44 \pm 0.01$ & $7.46 \pm 0.02$ \\
\hline $\mathrm{PCO}_{2}(\mathrm{~mm} \mathrm{Hg})$ & $48 \pm 4$ & $42 \pm 1$ & $41 \pm 1$ & $39 \pm 1$ & $41 \pm 2$ & $43 \pm 4$ \\
\hline $\mathrm{PO}_{2}(\mathrm{~mm} \mathrm{Hg})$ & $84 \pm 5$ & $88 \pm 3$ & $97 \pm 5$ & $94 \pm 3$ & $97 \pm 5$ & $100 \pm 5$ \\
\hline $\mathrm{Hb}(\mathrm{g} / \mathrm{dl})$ & $9.0 \pm 0.6$ & $10.2 \pm 0.6$ & $9.3 \pm 0.6$ & $9.5 \pm 1.0$ & $11.1 \pm 0.6$ & $9.7 \pm 0.3$ \\
\hline
\end{tabular}

* Values are means \pm SEM. Subgroup A, 11-26 days; B, 32-52 days, and C, 61-88 days of age.

Table 2. Hemodynamic preinfusion data and response at $60 \mathrm{~min}$ to $10 \mu \mathrm{g} / \mathrm{kg} / \mathrm{min}$ sodium nitroprusside infusion in all three age groups of the shunt and control lambs*

\begin{tabular}{|c|c|c|c|c|c|}
\hline & & Pre & & Nitr & \\
\hline & suogroups & $\mathrm{S}$ & $\mathrm{C}$ & $\mathrm{S}$ & $\mathrm{C}$ \\
\hline Mean aortic pressure (mm $\mathrm{Hg}$ ) & A & $65 \pm 2$ & $72 \pm 2$ & $54 \pm 2 \dagger$ & $61 \pm 2 \dagger$ \\
\hline & B & $77 \pm 2$ & $78 \pm 4$ & $66 \pm 2$ & $65 \pm 3 \dagger$ \\
\hline & $\mathrm{C}$ & $74 \pm 3$ & $81 \pm 3$ & $66 \pm 4$ & $66 \pm 3 \dagger$ \\
\hline Mean left atrial pressure ( $\mathrm{mm}$ & A & $12 \pm 1$ & $8 \pm 2$ & $9 \pm 1$ & $7 \pm 2$ \\
\hline $\mathrm{Hg})$ & $\mathrm{B}$ & $14 \pm 1 \S$ & $7 \pm 1$ & $10 \pm 1 \S$ & $4 \pm 1$ \\
\hline & $\mathrm{C}$ & $14 \pm 3$ & $10 \pm 2$ & $11 \pm 2$ & $8 \pm 2$ \\
\hline Heart rate (beats/min) & A & $201 \pm 9$ & $208 \pm 12$ & $236 \pm 10$ & $267 \pm 17 \dagger$ \\
\hline & $\mathrm{B}$ & $181 \pm 12 \S$ & $140 \pm 10+$ & $214 \pm 9$ & $212 \pm 8 \dagger \ddagger$ \\
\hline & $\mathrm{C}$ & $161 \pm 20 \S$ & $111 \pm 4 末$ & $219 \pm 5 \dagger$ & $183 \pm 9+7$ \\
\hline Systemic blood flow $(\mathrm{ml} / \mathrm{min} / \mathrm{kg})$ & A & $154 \pm 19$ & $202 \pm 18$ & $189 \pm 20$ & $220 \pm 19$ \\
\hline & $\mathrm{B}$ & $102 \pm 11 \S$ & $133 \pm 7 \ddagger$ & $102 \pm 11 \ddagger$ & $128 \pm 9 \ddagger$ \\
\hline & $\mathrm{C}$ & $122 \pm 9$ & $134 \pm 7 \ddagger$ & $137 \pm 15 \ddagger$ & $141 \pm 13 \ddagger$ \\
\hline Pulmonary blood flow $(\mathrm{ml} / \mathrm{min} /$ & A & $291 \pm 27 \S$ & $202 \pm 18$ & $314 \pm 29 \S$ & $220 \pm 19$ \\
\hline $\mathrm{kg})$ & B & $236 \pm 16 \S$ & $133 \pm 7 \ddagger$ & $236 \pm 11 \S$ & $128 \pm 9 \ddagger$ \\
\hline & $\mathrm{C}$ & $234 \pm 16 \S$ & $134 \pm 7 \ddagger$ & $247 \pm 13 \S$ & $141 \pm 13 \ddagger$ \\
\hline Systemic resistance $(\mathrm{mm} \mathrm{Hg}$. & A & $425 \pm 61$ & $348 \pm 35$ & $286 \pm 35$ & $276 \pm 34$ \\
\hline $\mathrm{min} \cdot \mathrm{kg} / \mathrm{liter})$ & $\mathrm{B}$ & $717 \pm 71 \ddagger \S$ & $473 \pm 27$ & $609 \pm 64 \ddagger \S$ & $415 \pm 21$ \\
\hline & $\mathrm{C}$ & $576 \pm 58$ & $520 \pm 61$ & $463 \pm 69$ & $429 \pm 27$ \\
\hline Pulmonary resistance $(\mathrm{mm} \mathrm{Hg}$. & A & $55 \pm 14$ & $70 \pm 15$ & $37 \pm 8$ & $54 \pm 11$ \\
\hline $\mathrm{min} \cdot \mathrm{kg} / \mathrm{liter})$ & B & $61 \pm 10$ & $82 \pm 23$ & $52 \pm 11$ & $76 \pm 6$ \\
\hline & $\mathrm{C}$ & $38 \pm 5$ & $50 \pm 5$ & $32 \pm 6$ & $56 \pm 11$ \\
\hline
\end{tabular}

* Values are means \pm SEM. S, lambs with an aortopulmonary left to right shunt; C, control lambs. Subgroup A, 11-26 days; B, 32-52 days; C, 61-88 days. $n$ is as given in Table 1. Two-way analysis of variance with replication and unequal samples and the Newman-Keuls test using rank sums: versus preinfusion value: $\dagger p<0.05$; versus lambs of subgroup A within the same group: $\neq p<0.05$; versus age-related lambs of the control group: $\S p<0.05$.

to right shunt flow was hardly affected at any time during the infusion.

Systemic vascular resistance decreased in all subgroups directly after the onset of the nitroprusside infusion. After this decrease, resistance returned towards preinfusion values, except for the systemic vascular resistance of subgroup B of the shunt lambs, which at $60 \mathrm{~min}$ was still significantly lower than the preinfusion value. After the end of the infusion, systemic vascular resistance increased abruptly and returned at $30 \mathrm{~min}$ after stopping the infusion to values that were, except for both subgroups A, significantly higher than preinfusion levels.

Pulmonary vascular resistance did not change significantly during the nitroprusside infusion in any of the subgroups.

\section{DISCUSSION}

Before the results are discussed, a few methodologic aspects of the study should be considered. We were not successful in setting up a group of newborn lambs with a substantial left to right shunt. They usually died shortly after the operation, probably because of their limited ability to increase systemic blood flow during an acute increase in preload (14).

It might be argued that our technique of calculating left to right shunt flow and fraction would lead to erroneous results because the electromagnetic flow transducer around the aorta measures left ventricular output minus coronary blood flow, which in this case is pulmonary blood flow minus coronary blood flow. Coronary blood flow can be substantially increased under stress (15). This was also seen in lambs with an aortopulmonary left to right shunt, in which coronary blood flow was measured with radionuclide-labeled microspheres (16). With a left to right shunt of about $50 \%$ of pulmonary blood flow, coronary blood flow was about twice as high as in age-related lambs without a shunt. Using the microsphere data to correct the left to right shunt flows obtained by the electromagnetic flow transducers in those studies-which is valid, because a good 
A
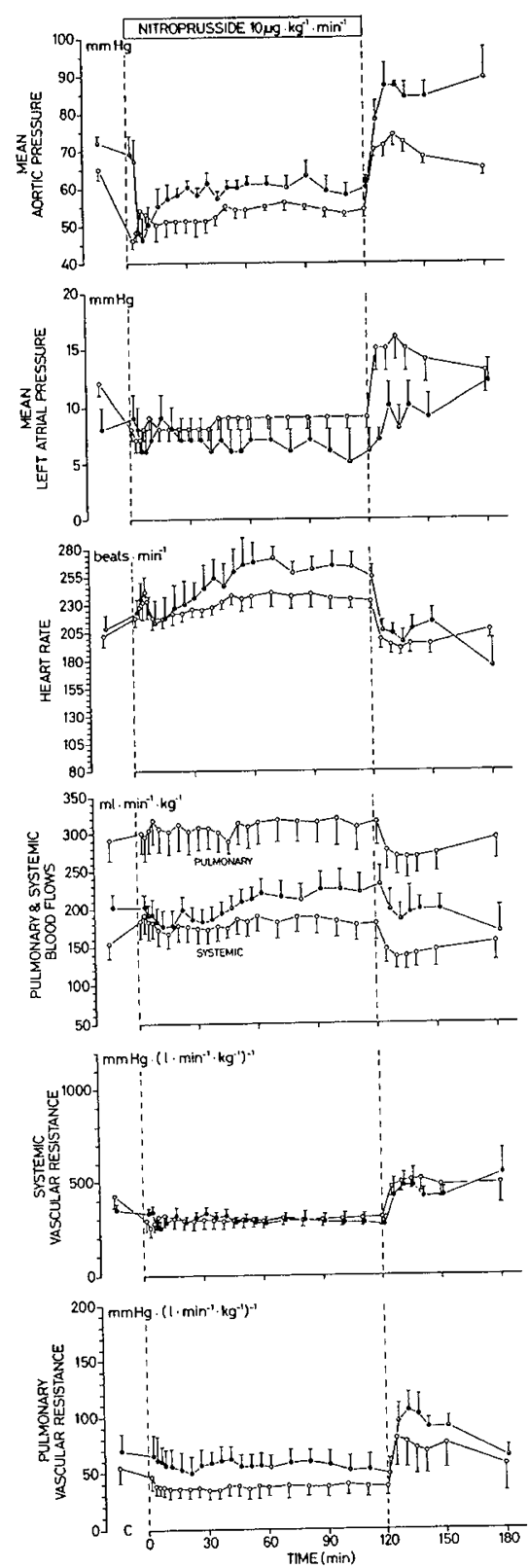

B

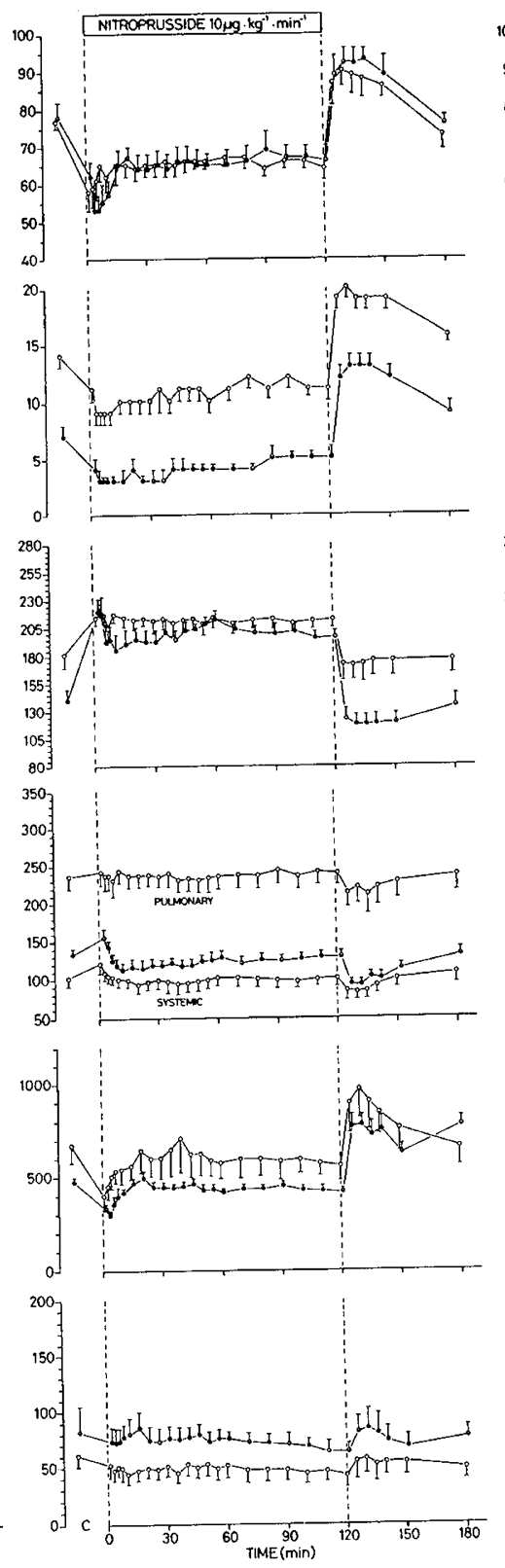

C

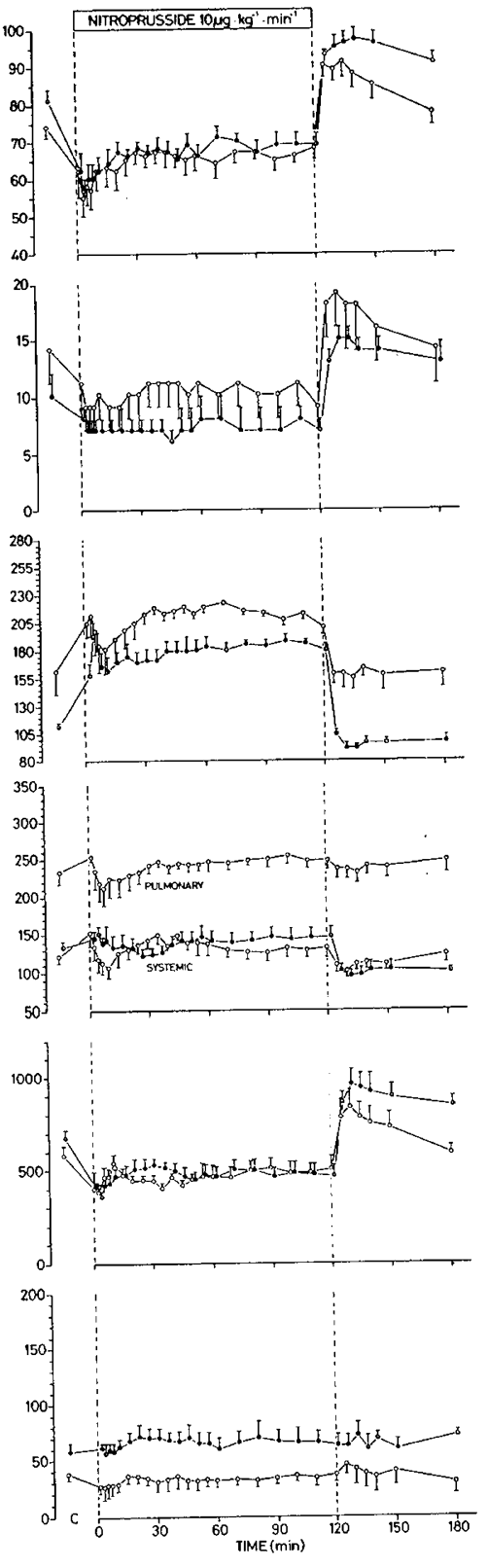

Fig. 1. Sequential effects of a 2 -h infusion of $10 \mu \mathrm{g} / \mathrm{kg} / \mathrm{min}$ of sodium nitroprusside, followed by a 1 -h recovery period, on mean aortic and left atrial pressures, heart rate, systemic and pulmonary blood flows, and systemic and pulmonary vascular resistances in shunt (O) and control lambs (O) of 11-26 days $(A), 32-52$ days $(B)$, and 61-88 days $(C)$ of age. Data are means \pm SEM.

correlation exists between both methods of determining flow (17) - resulted in only slightly larger left to right shunt fractions, i.e. $56 \%$ instead of $54 \%$ of pulmonary blood flow. Because the error was so small, we disregarded the coronary blood flow in the determination of the left to right shunt.

Although a left to right shunt of about $50 \%$ of pulmonary blood flow may seem small in comparison with the shunt sizes usually found in infants who show signs of circulatory congestion, we consider our experimental model well suited to evaluate this hemodynamic disorder and its treatment. We make this conclusion because our shunt lambs had dyspnea, probably caused by pulmonary congestion as a consequence of their higher left atrial pressures. Moreover, they had tachycardia, which may be explained by increased sympathetic stimulation, for instance by an increased release of catecholamines (18). Part of the difference in shunt size leading to circulatory congestion may be explained by the acute nature of the shunt in our lambs, contrary to the infant, who is able to adapt gradually to an increasing left to right shunt as pulmonary vascular resistance decreases steadily during neonatal life.

However, larger left to right shunts have been found in lambs with an artificial ventricular septal defect and a normal to high systemic blood flow (19). Despite the larger shunts, these lambs had substantially lower heart rates than our age-related lambs with an aortopulmonary left to right shunt (160 versus 190 beats/ min). This difference could be related to the differences in the two experimental models of a left to right shunt. As we previously reported, diastolic aortic pressures were significantly lower in lambs with an aortopulmonary left to right shunt than in control lambs (16). Inasmuch as coronary perfusion predominantly takes place during diastole, this would imply a decreased coronary driving pressure in the lambs with an aortopulmonary shunt. Therefore, the hemodynamic consequences of a ventricular septal defect and an aortopulmonary left to right shunt for the myocardium itself may be different.

We expected nitroprusside to decrease the systemic to pul- 
monary vascular resistance ratio and, therefore, shunt flow, especially because pulmonary resistance was already quite low and, therefore, probably less sensitive to further vasodilatation. The left to right shunt fraction and flow, however, did not change significantly during nitroprusside infusion. But after pooling all values, which was done because the hemodynamic responses to nitroprusside were similar in all age groups, the shunt fraction appeared to have decreased significantly during the first $5 \mathrm{~min}$ after the onset of the nitroprusside infusion (from $51 \pm 3$ to 40 $\pm \%, p<0.05$ ). Shunt flow also decreased (from $130 \pm 8$ to 96 $\pm 7 \mathrm{ml} / \mathrm{min} / \mathrm{kg}, p<0.025)$. After this decrease, however, the left to right shunt flow and fraction returned to their preinfusion levels in approximately 5-10 min, after which they stabilized.

The other cardiovascular responses induced by nitroprusside, which was administered in doses also used in children (20), were similar in shunt and control lambs and are in agreement with previous findings in newborn and age-related lambs (8). In all subgroups, the response to nitroprusside was characterized by a substantial drop in aortic pressure, followed by an increase in aortic pressure to values still below preinfusion levels. The cause of this increase in aortic pressure is an increase in systemic vascular resistance. From our data, it is unclear whether this is related to an increase in adrenergic stimulation in response to the sudden pressure decrease at the beginning of the infusion period (211), to sympathetic activation of renal structures (22), or to vasopression release after the decrease in aortic and left atrial pressures (23).

After the initial heart rate increase during the nitroprusside infusion, heart rate decreased in all subgroups. This decrease, however, did not result in heart rates below those before infusion, contrary to findings in 1-week-old lambs (8). It was suggested that an increased vasopressin release or stimulation of ventricular receptors was responsible for the decrease in heart rate. However, this is only feasible when in the shunt lambs a resetting of the receptors in question has taken place because of their substantially higher left atrial pressures as compared to lambs without a shunt.

The changes in systemic and pulmonary blood flow during nitroprusside infusion are probably not only related to the fluctuating heart rates, but also to a reduced venous return resulting from venous pooling (9).

In summary, these studies show that intravenous nitroprusside results in a complex, time-dependent pattern of hemodynamic changes. This pattern is not influenced by age or the presence of an aortopulmonary left to right shunt of about $50 \%$ of pulmonary blood flow. Although the left to right shunt flow decreased significantly early after the onset of the nitroprusside infusion, this decrease was of too short a duration to consider nitroprusside beneficial in these cases. Moreover, the potentially favorable effect of afterload reduction by nitroprusside on myocardial oxygen consumption is probably neutralized by the increase in heart rate. We conclude that nitroprusside should not be administered in the case of a left to right shunt with a normal pressure and systemic blood flow. However, the possibility cannot be ruled out that nitroprusside might be beneficial in cases with a normal arterial pressure and a decreased systemic blood flow. Then, however, in view of the hemodynamic effects of the large doses of sodium nitroprusside, the initial rate of administration should be slow.
Acknowledgments. The authors thank Ineke Wessels for assistance in preparing the manuscript, Eveline Eimers and Mrs. B. Gauw for secretarial help, and G. P. Messchendorp for the artwork.

\section{REFERENCES}

1. Miller RA, Vismara LA, Williams DO, Amsterdam EA, Mason DT 1976 Pharmacological mechanisms for left ventricular unloading in clinical congestive heart failure: differential effect of nitroprusside, phentolamine and nitroglycerin on cardiac function and peripheral circulation. Circ Res 39:127-133

2. Miller RA, Vismara LA, Zelis R, Amsterdam EA, Mason DT 1975 Clinical use of sodium nitroprusside in chronic ischemic heart disease: effects on peripheral vascular resistance and venous tone and on ventricular volume, pump and mechanical performance. Circulation 51:328-336

3. Benzing G III, Helmsworth JA, Schrieber JT, Loggie J, Kaplan S 1976 Nitroprusside after open-heart surgery. Circulation 54: 467-471

4. Synhorst DP, Lauer RM, Doty DB, Brody MJ 1976 Hemodynamic effects of vasodilator agents in dogs with experimental ventricular septal defects. Circulation 54:472-477

5. Beekman RH, Rocchini AP, Rosenthal A 1981 Hemodynamic effects of nitroprusside in infants with a large ventricular septal defect. Circulation 64 : 553-558

6. Beekman RH, Rocchini AP, Rosenthal A 1982 Hemodynamic effects of hydralazine in infants with a large ventricular septal defect. Circulation 65:523-528

7. Nakazawa M, Takao A, Chon Y, Shimizu T, Kanaya M, Momma K 1983 Significance of systemic vascular resistance in determining the hemodynamic effects of hydralazine on large ventricular septal defects. Circulation 68:420 424

8. Kuipers JRG, Sidi D, Heymann MA, Rudolph AM 1984 Effects of nitroprusside on cardiac function, blood flow distribution, and oxygen consumption in the conscious young lamb. Pediatr Res 18:618-626

9. Tinker JH, Michenfelder JD 1976 Sodium nitroprusside: pharmacology, toxicology and therapeutics. Anesthesiology 45:340-353

10. Sidi D, Kuipers JRG, Heymann MA, Rudolph AM 1982 Recovery of cardiovascular function in newborn lambs after thoracotomy. Pediatr Res 16:705710

11. Sidi D, Kuipers JRG, Heymann MA, Rudolph AM 1983 Effects of ambient temperature on oxygen consumption and the circulation in newborn lambs at rest and during hypoxia. Pediatr Res 17:254-258

12. Winer BJ 1971 Statistical Principles in Experimental Design. McGraw Hill, New York, pp 752-812

13. Zar JH 1974 Biostatistical Analysis. Prentice Hall Inc, Englewood Cliffs, NJ, pp 151-155

14. Klopfenstein HS, Rudolph AM 1978 Postnatal changes in the circulation and the responses to volume loading in sheep. Circ Res 42:839-845

15. Sidi D, Kuipers JRG, Teitel D, Heymann MA, Rudolph AM 1983 Developmental changes in oxygenation and circulatory responses to hypoxemia in lambs. Am J Physiol 245:H674-H682

16. Toorop GP, Hardjowijono R, Dalinghaus M, Gerding AM, Koers JH, Zijlstra WG, Kuipers JRG 1987 Myocardial blood flow and $\mathrm{VO}_{2}$ in conscious lambs with an aortopulmonary shunt. Am J Physiol 252:H681-H686

17. Kuipers JRG, Sidi D, Heymann MA, Rudolph AM 1982 Comparison of methods of measuring cardiac output in newborn lambs. Pediatr Res 16:594 598

18. Fujisawa A, Sasayama S, Takahashi M, Nakamura M, Ohyagi A, Lee JD, Yui Y, Kawai 1984 Enhancement of left ventricular contractility after opening of an arterio-venous fistula in dogs. Cardiovasc Res 18:51-59

19. Boucek MM, Chang R, Synhorst DP 1984 Vasodilators and ventricular septal defect: comparison of prazosin, minoxidil, and hydralazine in a chronic lamb model. Pediatr Res 18:859-864

20. Bennett NR, Abbott TR 1977 The use of sodium nitroprusside in children. Anaesthesia 32:456-463

21. Pettinger WA, Campbell WB, Keeton K 1973 Adrenergic component of renin release induced by vasodilating antihypertensive drugs in the rat. Circ Res 33:82-86

22. Kaneko Y, Ikedo T, Takedo T, Ueda H 1967 Renin release during acute reduction of arterial pressure in normotensive subjects and patients with renovascular hypertension. $\mathrm{J}$ Clin Invest 46:705-716

23. Brennan LA Jr, Malvin AL, Jochim KE, Roberts DE 1971 Influence of right and left atrial receptors on plasma concentration of $\mathrm{ADH}$ and renin. Am $\mathrm{J}$ Physiol 221:273-278 